Sofija GEORGIEVSKA

UDK: $364-785.6-056.83$

Original research paper

SYSTEMIC FAMILY THERAPY WORKING WITH DRUG USERS

\begin{abstract}
After years of medical research, it is clear that drug addiction is a complex multifactorial biological and behavioural disorder. Scientific advances have made it possible to develop treatments that help normalize the functioning of the brain of those affected and support them in changing their behaviour. Providing evidence-based treatments now helps millions of people regain control of their lives. It is the psychosocial work with these people that provides such methods that in cooperation with the addict, who must be prepared for this type of cooperation, can produce positive effects for him and the environment, including the family that is always most affected by the addictive problem.

This paper deals with some of those methods, that is, systemic family therapy that would enable progress in the addict's behaviour, his/her desire to change behaviour or treatments for relapse and prevention of relapse and recurrent behaviour. All this composition of psychosocial work, work through family therapies, and control over the addict enabled and assisted by official health and civic associations contribute to the formation of an overall strategy to help addicts and reduce the number of addicts in the country.
\end{abstract}

Keywords: SYSTEMIC FAMILY THERAPY, TREATMENT, ADDICTS

Family dynamics changed dramatically in the last few decades, affecting the way we live and the behaviour and roles of the family. The modern family unit may include single-parent families, increased divorce rates, and same-sex marriage. Regardless of the different ways in which a family unit changes, family therapy is still a useful component of substance abuse treatment. In fact, research has shown that treatment behaviour in healthcare, which includes family therapy, is a better treatment when combined with individual treatment so it can reduce recurrence rates, reduce psychiatric symptoms and reduce stress (Rowe, CL, La Greca, AM and Alexandersson, A., 2010)

Addiction puts family members under a lot of stress, disrupts routines, and causes disturbing or even frightening experiences. As a result, family members develop an unhealthy strategy for dealing with the problem, because they are trying to maintain balance in the family. The family unit becomes a fragile and dysfunctional system, and this often inadvertently contributes to addiction because the family adopts destructive behaviour. Children in the family are particularly affected by addiction. Substance abuse as a disease dis- 
rupts normal development and leads to a higher risk of physical, mental, and emotional health problems. An example is the problems of children of an addicted parent who often have difficulties in school, social life, and it is likely that it is these children who will be able to become addicted or addicted in the future.

\subsection{Impact of psychotropic substance abuse on families}

Although the effects of substance abuse vary based on family structure, drug or alcohol dependence still affects family dynamics in several ways (Substance Abuse Treatment and Family Therapy, 2015).

\section{Negative emotions}

As a result of substance abuse, family members often experience negative emotions such as anger, resentment, anxiety, worry, guilt, and discomfort.

\section{Security}

In some cases, the safety of other family members may be at risk of being abused by psychotropic substances. Children or spouses may also feel the need to receive legal protection for fear of the actions of their loved ones.

\section{Responsibilities}

Certain family members inherit too many responsibilities or ageappropriate responsibilities. This can cause children or spouses to become overwhelmed, anxious, and resentful.

\section{Communication}

When a family member abuses drugs, communication within the family is often negative, and positive interaction is very limited. In addition, the needs, worries, and desires of family members, other than the abuser, may be overlooked.

\section{Structure and boundaries}

Homes where there is substance abuse often lack structure with minimal parental involvement and loosely existing or non-existent boundaries. This results in confusion in children and negative/inappropriate behaviour. Parents and siblings can also adopt behavioural opportunities that contribute to substance abuse.

\section{Denial}

In many cases, when a child has a problem with psychotropic substance abuse, parents will deny that there is a problem. This may be because they don't want to, they can't face the problem or they just can't see it clearly.

\section{Connections}

Substance abuse creates damaged relationships that can continue through multiple generations of the family through negative modelling of be- 
haviour. In addition, drug or alcohol addicts often isolate themselves from other family members and spend most of their social time with other drug addicts in their closed group.

In families where one or more members have a substance abuse problem, substance abuse treatment and family therapy can be integrated to provide effective solutions to multiple problems. Social service counsellors and psychotherapists from both disciplines have similar professional training. Consequently, integrated treatment models serve as a guide for combined treatment approaches, especially when it comes to family therapy. The theoretical basis of many models is given along with the techniques and strategies most commonly used. The client's range of needs, multiple family influences, and differences in counsellor training and priorities, along with the severe nature of most psychotropic substance abuse problems, suggest that family therapy and addiction treatment fields need to be closely linked. (Klarić, D., 2007). Integrated family treatment models effectively provide services for addicts and their families.

\subsection{Compatibility of family behaviour with the addict}

Problems often arise when one has to adjust to a dysfunction in the family system. Appropriate behaviours are learned thoughts, attitudes, and behaviours that lead to the neglect of one's own needs and desires in favour of an obsessive concern for a loved one's problems. Appropriate behaviours include:

Constant and obsessive desire of family members to help the drug addict member.

Living in denial of the dependence of a family member in order to avoid the consequences both personally and in the social environment itself.

The family reacts violently or irrationally to addiction-related events.

$>$ The family has the same low self-esteem as the addict as a result of neglecting their own physical, spiritual and emotional needs while focusing exclusively on the addict and his needs.

$>$ Involvement in the own unhealthy behaviour of other family members that seemingly helps in dealing with reality.

$>$ Recognition of the problem and active participation of other family members by involving the addict in all family activities, responsibilities and rights arising from living together (Klein, G. 1999.).

The purpose of psychosocial work with drug addicts through family type therapy is the basis of rehabilitation and abstinence, which also gives the family, the environment and the addict as an individual not to feel rejected, ie not to be outside the social collective community. 


\subsection{Benefits of family therapy}

There are many benefits to family therapy, especially when used in the treatment of addiction. Family therapy helps family members heal and recover as a group. The therapeutic environment provides a safe space for everyone to learn how to adapt to the recovery of a loved one from addiction and mental illness. Family therapy sessions are also designed to help family members make specific, positive changes to improve the home environment as well as heal relationships within the family unit. Family therapy usually involves the psychotropic substance addict and at least one other family member. This could be a spouse, parent, sibling, or someone else who has a close relationship with the person being treated.

Numerous studies demonstrate the positive impact a family can have on a family member's recovery from addiction. Many authors believe that without family therapy drug abuse is not even possible to cure and at the same time emphasize the many benefits of family involvement in recovery (Beavers, R., \& Hampson, R. B., 2000).

- Supporting the addict through motivation during treatment,

> Verbal learning about addiction and its effects on the family, as well as understanding how family treatment works and what to expect from that approach during and after therapy.

$>$ Enabling family members to express feelings and concerns and ask questions about a loved one's addiction,

$>$ Offering the desired high degree of adequate support after treatment, ie weakening the feelings of fear, anger, stress and confusion related to addiction,

> Opportunity for family members to develop skills and strategies to help their loved one stay on the road to recovery,

Improvements in family communication skills,

> Ability to address all mental health issues within the family system, such as depression or anxiety, which may interfere with family communication and contribute to addict behavior.

According to social workers in collaboration with psychologists from the relevant centers, family therapy shows positive results for problems with substance use and coexisting disorders such as depression, neglect, unemployment and other types of family conflict. When family therapy is chosen as the most appropriate model for combating addiction, especially when it is possible, ie when the family exists and has a real desire and need to overcome a conflict situation that is really very difficult for other members and the addict himself, and this implies certain expectations and assumptions (Rowe, CL, La Greca, AM and Alexandersson, A., 2010):

Family involvement. Family addiction therapy usually starts after the user enters this form of treatment to overcome the abuse of psychotropic 
substances and makes progress. This means that it is a laborious, complex treatment for a long period of time from several weeks to several months and even years. It usually involves the client in the treatment of drug abuse and at least one other family member. This could be a close, extended, family member or other person who is significantly close to the client.

* Life skills. During therapy, the counsellor has a responsibility to help family members as they acquire new skills, new lifestyles and all together need to learn how to apply them. This helps to create a healthier interaction at home that improves the overall environment. Counsellors also teach family members how to communicate more effectively and behave in ways that support the client's recovery, rather than hindering it.

* Behavioural changes. Emergency management of the addict relapse, abstinence crises, and depressive crises is also used in family therapy to help the addict as he or she develops behavioural goals that encourage abstinence from any substance use. This improves progress and helps to solve basic problems and overcome damaged family relationships.

* Goal setting. Family members are required to set goals related to the roles they play within the family unit. For example, parents set goals related to their parenting roles, siblings set goals related to being a sibling, and so on. These goals are considered during each session, and family therapy helps the whole family district, not just the addict. Goals are the basic motivator that enables the drawing of an appropriate path to overcoming the problem and the disease and provides the desire to reach the end of the road.

\subsection{Danger of non-acceptance of therapy by a family member}

In some cases, a family member may not be willing to participate in this type of therapy. This is often due to fear, scepticism that counselling will not make a difference, or sheer exhaustion from ongoing efforts. Some may also be concerned about a number of things, such as the fear of entangling that member in therapy that will include his or her behaviour, and then the danger of facing difficult problems that they would not want to face. Family therapy means that other family members are also involved in the psychosocial work with the addict and they have to face the alleged disclosure of family secrets such as abuse, addiction or illegal activities. If this happens, it is helpful for the individual to meet with the counsellor on an individual basis to explain his or her concerns, to consider the intentions and benefits of family counselling, and to encourage participation. Ultimately, the decision to participate must be made voluntarily, but additional education and encouragement from an addiction specialist can help persuade unprepared family members to accept family therapy. In reality, it can be very difficult to get unprepared family members 
involved in treatment. The main role in such developments is played by psycheducational workers and motivational interviewing of those members who can help weaken the resistance of these members.

In psychosocial work there are both form and psych-educational workshops that explain the therapy and give the importance and far-reaching benefits of family involvement in recovery. Motivational interviewing can help a family member work through recovery ambivalence and help them identify their own motivations for change, that is, understand and accept the goals of this form of family therapy in the case of drug addiction.

\subsection{The goals of family addiction therapy}

According to the Mental Health and Psychosocial Work Services, there are two main goals of addiction family therapy.

1. Providing useful support for the addict during the period of abstinence and treatment. Family therapy reduces the chances of relapse, helps to develop and maintain positive changes in behavior and attitude, and promotes long-term recovery of the individual in the treatment of substance abuse.

2. An option such as improving the emotional health of the family as a whole is then assumed. Therapy helps family members build trust and promote forgiveness for past behaviors in both addicts and family members. It can also provide peace and resolve conflicts or feelings of anger, frustration and sadness. In addition, family therapy aims to reduce as much as possible the effects of the current crisis and the abstinence crises that follow and encourages participants to emerge from negative emotions (Beavers, R., \& Hampson, R. B., 2000).

\subsection{Danger of relapse into psychotropic substances}

Health, the home environment and the community are the cornerstones of recovery life, but it is important to understand that failures, which are relatively common, are behaviours that can lead to recurrent behaviour, are a normal part of recovery. Addiction recurrence rates are similar to those for other chronic diseases, such as heart disease and diabetes. Between 40 and 60 percent of people who recover will relapse at some point. It is important for the individual recovering and family members to realize that relapse and other barriers are not the end of the addiction process. Relapse is now considered an opportunity to evaluate the recovery plan and determine what caused such behaviour, and then take steps to develop recognition of triggers that led to relapse (Beavers, R., \& Hampson, R. B., 2000).

People who view failure as a personal failure are likely to ignore all the positive benefits of recovery and may feel that sobriety or non-drug use is too difficult to achieve. In contrast, those who see failure as a catalyst for reevaluating the recovery plan, identifying the causes of the recurring behaviour 
that led to the failure, are more likely to return to the path to recovery stronger than before, with greater determination and motivation to achieve long-term abstinence. Involving the family in treatment and recovery has been shown to help prevent relapse, but realistically re-access to drugs is always possible.

Knowing the stages of relapse and the signs associated with each stage can help family members recognize the impending obstacle, help their member avoid relapsing behavior, and thus gain the support needed to return to the right way.

\section{References:}

BARLOW, D. H. (2010). Negative effects of psychological treatments: A perspective. American Psychologist, 65, 1, 13-20.

BEAVERS, R., \& HAMPSON, R. B. (2000). The beavers systems model of family functioning. Journal of Family Therapy, 22(2), 128-143.

KLARIĆ, D. (2007.): Droga - nerješiv problem; priručnik za edukatore, Dvotočka, Zagreb.

KLEIN, G. (1999.): Sources of power: how people make decisions, MIT press.

Rowe, C. L., LA GreCA, A. M. AND AleXANDERSSON, A. (2010), 'Family and individual factors associated with substance involvement and PTS symptoms among adolescents in greater New Orleans after Hurricane Katrina', Journal of Consulting and Clinical Psychology 78, pp. 806-817.

Substance Abuse Treatment And Family Therapy, (2015), U.S. DEPARTMENT OF HEALTH AND HUMAN SERVICES Substance Abuse and Mental Health Services Administration Center for Substance Abuse Treatment 